\title{
CS Resarach Soure \\ Factors Associated with Exclusive Breastfeeding in the State of Kuwait
}

\section{Tahani Alwaalan ( $\nabla$ tahanialwaalan@gmail.com )}

Kuwait Institute for Scientific Research https://orcid.org/0000-0002-5321-6046

\section{Tareq Al-Aati}

Kuwait Institute for Scientific Research

\section{Salwa Al-Mutairi}

Kuwait Institute for Scientific Research

\section{Research}

Keywords: Breastfeeding, Infant growth, exclusive, formula-feed

Posted Date: November 9th, 2021

DOI: https://doi.org/10.21203/rs.3.rs-1035891/v1

License: (c) (i) This work is licensed under a Creative Commons Attribution 4.0 International License. Read Full License 


\section{Abstract}

Aim: To determine the factors influencing breastfeeding continuation for the first six months of a baby's life.

Method: A cross-sectional study was conducted by the research team via an interview-based questionnaire and interviewer at Al-Sabah Maternity Hospital. A total of 316 Kuwaiti and non-Kuwaiti subjects participated in this study. Chi-square tests and logistic regression analysis were conducted to examine the factors influencing breastfeeding.

Results: A total of 196 (62\%) of the mothers practiced any feeding, including formula and/or breast milk, only $12.3 \%$ of the mothers exclusively breastfed their babies for the first six months of life. Highly educated mothers were less likely to breastfeed than less educated mothers (OR: 0.14; 95\% Cl: 0.05-0.45). Not using pacifiers was positively associated with breastfeeding (OR: 2.15; 95\% Cl: 1.32-3.51). More than a third of the mothers reported stopping breastfeeding due to lack of lactation places in public and workplaces (50\%) and insufficient milk production to support infant growth (32\%).

Conclusion: Our findings highlight the importance of creating a supportive environment in workplaces and public areas to encourage mothers to breastfeed. Interventions for enhancing knowledge and promoting breastfeeding are advised, focusing on factors associated with early cessation.

\section{Introduction}

The World Health Organization (WHO) recommends initiating breastfeeding within one hour of birth and exclusive breastfeeding up to 6 months of age [1]. Breastfeeding is given great emphasis due to its benefits to mothers and their children. Studies have shown that breastfeeding protects mothers from premenopausal breast cancer, ovarian cancer, retained gestational weight gain, type 2 diabetes, myocardial infarction, and metabolic syndrome [2]. Breastfeeding is also beneficial to infants; breast milk contains essential nutrients that are important for the physical and mental development of the baby. It also protects babies against certain infections and other conditions in early childhood [3].

On the other hand, infants who did not receive breast milk are more likely to suffer from infectious morbidity, childhood obesity, diabetes, leukemia, and sudden infant death syndrome [3]. In 2019, 30.5\% of children and adolescents aged $6-18$ years in Kuwait were obese, and the incidence of type II diabetes was reported as 2.56 per 100,000 Kuwaiti children and adolescents per year [4]. Therefore, understanding the factors associated with breastfeeding practices among mothers could be important for diabetes and obesity prevention in Kuwait.

In 2010 , only $10.5 \%$ of the mothers in Kuwait exclusively breastfed their babies until six months [5]. Research has shown that several factors could play an important role in preventing mothers from breastfeeding [6]. Some factors are: level of education, the feasibility of breastfeeding at work, selfperceived adequacy of breast milk, separate housing, and higher maternal age [6]. Whether these factors 
affecting mothers feeding practices in Kuwait need further investigations. Understanding the contributing factors to breastfeed will significantly impact children, mothers, and the community. Therefore, the current study aimed to determine the factors influencing breastfeeding continuation for the first six months of the baby's life in Kuwait.

\section{Materials And Methods}

Procedures for recruitment were established for mothers and their newborn infants in Al-Sabah Maternity Hospital. This hospital is one of the biggest general hospitals in Kuwait that offers health-related services to the population of the Capital governorate. Mothers who had full-term babies (37+ weeks) and babies with normal birth weight $(\geq 2.5 \mathrm{Kg}$ ) were eligible to participate in the study. Of the total 612 mothers informed, only 316 agreed to participate and signed the consent form. Information was collected using an interview-based questionnaire to ensure the questions were fully understood and enhance the answers' quality. The questionnaire included three sections. The first section contained information about the newborn, such as birth date, sex, weight, height, and gestational age. The second and third sections addressed general information concerning the mother and father, such as their birth date, nationality, weight, height, education level, monthly income, and residence. This study was approved by the Ethical Committee at the Ministry of Health in Kuwait.

\section{Statistical Analysis}

We first described the characteristics of study participants using counts and percentages. We then compared the proportions of participants' characteristics by feeding practices using chi-square and Fisher exact tests. Finally, the associations between the significant variables from the chi-square test and feeding practices (any breastfeeding vs. bottle-feeding) were performed using a logistic regression model. All statistical analyses were performed using SAS version 9.4 (SAS Institute). All tests were two-sided, and a $p$-value of $<0.05$ was considered statistically significant.

\section{Results}

The characteristics of study participants are presented in Table 1 . The majority of the participants were aged less than 30 years old (67.1\%), Kuwaiti nationals (79.1\%), had a bachelor's degree or above (50.6\%), had a full-time job or a student (75.6\%), had an income of 1500 Kuwaiti Dinar or above (86.1\%), and lived with their families (54.7\%). Three-fourths of the mothers had a normal birth $(75 \%)$, and more than half of the mothers gave birth to boys (53.2\%) and used pacifiers for their babies (57.0\%). 
Table 1

Characteristics of participants $(\mathrm{N}=316)$

\begin{tabular}{|c|c|c|}
\hline Characteristic & $\mathbf{N}$ & $(\%)$ \\
\hline \multicolumn{3}{|l|}{ Maternal age range (year) } \\
\hline$<30$ & 212 & 67.1 \\
\hline$\geq 30$ & 104 & 32.9 \\
\hline \multicolumn{3}{|l|}{ Maternal education level } \\
\hline High school or below & 35 & 11.1 \\
\hline College student or diploma & 121 & 38.3 \\
\hline Bachelor' degree or above & 160 & 50.6 \\
\hline \multicolumn{3}{|l|}{ Maternal occupation } \\
\hline Student or employed & 239 & 75.6 \\
\hline Unemployed & 77 & 24.4 \\
\hline \multicolumn{3}{|c|}{ Family monthly income (Kuwaiti Dinar) } \\
\hline$<1500$ & 44 & 13.9 \\
\hline$\geq 1500$ & 272 & 86.1 \\
\hline \multicolumn{3}{|l|}{ Nationality } \\
\hline Kuwaiti & 250 & 79.1 \\
\hline Non-Kuwaiti & 66 & 20.9 \\
\hline \multicolumn{3}{|l|}{ Housing } \\
\hline Separate house & 143 & 45.3 \\
\hline Family related & 173 & 54.7 \\
\hline \multicolumn{3}{|l|}{ Delivery mode } \\
\hline Normal & 237 & 75.0 \\
\hline Caesarean section & 79 & 25.0 \\
\hline \multicolumn{3}{|l|}{ Sex of infant } \\
\hline Girl & 148 & 46.8 \\
\hline Boy & 168 & 53.2 \\
\hline \multicolumn{3}{|l|}{ Pacifier use } \\
\hline Yes & 180 & 57.0 \\
\hline
\end{tabular}




\begin{tabular}{|lll|}
\hline Characteristic & N & (\%) \\
\hline No & 136 & 43.0 \\
\hline
\end{tabular}

About $38 \%$ of the mothers reported stopping breastfeeding after some time. The reasons behind abstaining from breastfeeding were mothers had no time to breastfeed due to return to work or school, milk was insufficient, no place for breastfeeding in public places, babies not gaining enough weight, and inadequate knowledge of how to breastfeed (Figure 1).

Table 2 presents the chi-square tests of feeding practices by participants' characteristics. Only maternal education level $(P=0.0007)$ and pacifier use $(P=0.002)$ were significantly associated with breastfeeding continuation for the first six months of a baby's life. About $89 \%$ of less-educated mothers reported that they breastfed their infants compared to $62 \%$ of the highly-educated mothers. Approximately half of the mothers (54.4\%) who used pacifiers to their infants practiced breastfeeding compared to $72 \%$ who did not use pacifiers. Maternal occupation may also play a role in breastfeeding $(P=0.059)$, employed or student mothers were less likely to breastfeed their infants than unemployed mothers. 
Table 2

Chi-square tests of feeding practices by participants' characteristics

\begin{tabular}{|c|c|c|c|}
\hline Characteristic & $\begin{array}{l}\text { Any breastfeeding } \\
\mathrm{N}(\%)\end{array}$ & $\begin{array}{l}\text { Formula feeding } \\
\mathrm{N}(\%)\end{array}$ & $P$ Value ${ }^{*}$ \\
\hline Maternal age range (year) & & & 0.46 \\
\hline$<30$ & $128(60.4)$ & $84(39.6)$ & \\
\hline$\geq 30$ & $68(65.4)$ & $36(34.6)$ & \\
\hline Maternal education level & & & 0.0007 \\
\hline High school or below & $31(88.6)$ & $4(11.4)$ & \\
\hline College student or diploma & $66(54.5)$ & $55(45.5)$ & \\
\hline Bachelor or above & 99 (61.9) & $61(38.1)$ & \\
\hline Maternal occupation & & & 0.059 \\
\hline Student or employed & $141(59.0)$ & $98(41.0)$ & \\
\hline Unemployed & $55(71.4)$ & $22(28.6)$ & \\
\hline Monthly income (Kuwaiti Dinar) & & & 0.62 \\
\hline$<1500$ & $29(65.9)$ & $15(34.1)$ & \\
\hline$\geq 1500$ & $167(61.4)$ & $105(38.6)$ & \\
\hline Nationality & & & 0.57 \\
\hline Kuwaiti & $153(61.2)$ & $97(38.8)$ & \\
\hline Non-Kuwaiti & $43(65.2)$ & $23(34.8)$ & \\
\hline Housing & & & 0.35 \\
\hline Separate house & $93(65.0)$ & $50(35.0)$ & \\
\hline Family related & $103(59.5)$ & $70(40.5)$ & \\
\hline Delivery mode & & & 0.60 \\
\hline Normal & 149 (62.9) & $88(37.1)$ & \\
\hline caesarean Section & $47(59.5)$ & $32(40.5)$ & \\
\hline Sex of infant & & & 0.42 \\
\hline Girl & 88 (59.5) & $60(40.5)$ & \\
\hline Boy & $108(64.3)$ & 60 (35.7) & \\
\hline Pacifier use & & & 0.002 \\
\hline
\end{tabular}




\begin{tabular}{|lll|}
\hline Characteristic & $\begin{array}{l}\text { Any breastfeeding } \\
\mathbf{N}(\%)\end{array}$ & $\begin{array}{l}\text { Formula feeding } \\
\mathbf{N}(\%)\end{array}$ \\
\hline Yes & Value $^{*}$ \\
\hline No & $98(54.4)$ & $82(45.6)$ \\
\hline${ }^{*}$ Fisher's exact test & $98(72.1)$ & $38(27.9)$ \\
\hline
\end{tabular}

On multivariable logistic regression analysis, maternal education level and pacifier use were significant factors for breastfeeding (Table 3). Mothers who did not use pacifiers for their infants were two times more likely to breastfeed than mothers who used pacifiers (OR: 2.15; 95\% Cl: 1.32-3.51). Compared with less educated mothers, college student mothers and mothers who had diplomas were $86 \%$ (OR: 0.14; $95 \%$ Cl: $0.05-0.45$ ) less likely to breastfeed. Similarly, mothers with a bachelor's degree or above were $81 \%$ (OR: $0.19 ; 95 \% \mathrm{Cl}: 0.06-0.63)$ less likely to breastfeed than mothers with a high school or below.

Table 3

Odds Ratios ( $95 \%$ Confidence Intervals) of the associations between significant predictors and continuation of breastfeeding for the first six months.

\begin{tabular}{|ll|}
\hline Variable & OR $^{\mathrm{a}}(95 \% \mathrm{Cl})$ \\
\hline Maternal education level & \\
\hline High school or below & 1.00 \\
\hline College student or diploma & $0.14(0.05-0.45)^{*}$ \\
\hline Bachelor's degree or above & $0.19(0.06-0.63)^{*}$ \\
\hline Monthly income (KD) & 1.00 \\
\hline$<1500$ & $1.38(0.61-3.17)$ \\
\hline$\geq 1500$ & 1.00 \\
\hline Pacifier use & $2.15(1.32-3.51)^{*}$ \\
\hline Yes & \\
\hline No & \\
\hline a Adjusted for maternal education level, monthly income, and pacifier use. \\
\hline *Statistically significant at $P$ Value $<0.01$
\end{tabular}

\section{Discussion}


The present study determined the factors influencing breastfeeding and further evaluated these factors with the continuation of breastfeeding in the first six months of an infant's life. Our study has shown that $12.3 \%$ of the mothers in Kuwait exclusively breastfed their babies until six months. This prevalence was higher than that reported in Kuwait in $2007 / 2008$, with only $2 \%$ of the participants exclusively breastfed for six months [7]. In this study, the prevalence of any breastfeeding was also higher than that reported previously, $62 \%$ vs. $39.0 \%$, respectively. The higher prevalence of breastfeeding in our study compared to the previous studies shows the successful efforts made by the Ministry of Health $(\mathrm{MOH})$ in Kuwait to raise the awareness of the importance of breastfeeding [8]. Since 2012, the $\mathrm{MOH}$ has integrated specialized breastfeeding clinics in all public hospitals. These clinics are equipped with nurses who are specialized in breastfeeding and postpartum care and are provided with posters and brochures explaining the benefits of breastfeeding. A campaign on the benefits of breastfeeding has also been launched to spread information in simple and clear messages in multiple languages to cover all members of this diverse community [9]. This study suggests that the efforts made by the $\mathrm{MOH}$ were successful in increasing the rate of breastfeeding among women living in Kuwait

The prevalence of any breastfeeding varied across the Gulf Cooperation Council (GCC) countries ranging from $40-62 \%$. The lowest rate was observed in Saudi Arabia (Jeddah) [10] and the United Arab Emirates [9]; $40 \%$ and $40.8 \%$ of the participants are breastfed until their child reached the age of six months, respectively. Followed by Qatar, 49.9\% of Arab mothers have continued breastfeeding for six months [11]. The highest breastfeeding rates were observed in Kuwait and Oman, where $62 \%$ and $60.4 \%$ of the mothers breastfeed their babies until six months of age, respectively [12].

We found that higher maternal education and pacifier use were the two significant factors negatively associated with continuing breastfeeding at six months in Kuwait. This highlights the need to inform mothers of the negative consequence of early pacifier use. Consistent findings were observed in Kuwait [9], Saudi Arabia, and Qatar [13]. Literature has found other factors considered barriers to continued breastfeeding; include mothers' perception of pain, body image, body changes, embarrassment from breastfeeding in public, and breastfeeding at work [14]. However, these factors were out of the scope of our study and should be assessed in future work.

More than a third of the mothers in our study reported stopping breastfeeding after some time. Consistent with other studies in the GCC [9-12-13], we found that mothers having to return to work or school and no appropriate places for breastfeeding in public places were two of the most important reasons for stopping breastfeeding. This shed light on the importance of providing breastfeeding break time and creating suitable areas for lactating mothers in workplaces. These lactation rooms should be equipped with breast pumps, refrigerators, and necessities to encourage nursing mothers to express their milk during workdays. This will help mothers maintain their milk production, relieve breast engorgement during long working hours, and appropriately store breast milk for babies to feed when the mother is at work [15]. Public places should also consider establishing clean, comfortable, and private lactation rooms to encourage mothers to breastfeed. The other two reasons reported by mothers for stopping breastfeeding were that the milk was insufficient for the baby and the baby is not gaining enough weight. Despite the 
MOH's great effort on breastfeeding as reported earlier, our study found that there are still more gaps in mothers' knowledge regarding breastfeeding.

\section{Conclusions}

The percentage of exclusive breastfeeding women in Kuwait appears to be slightly increasing. Implementing the World Health Organization 10 Steps for Successful Breastfeeding program in Kuwait's Ministry of Health hospitals in 2012 [8] seems to successfully raise awareness and knowledge of breastfeeding among mothers in Kuwait. However, there is still a gap in knowledge regarding breastfeeding practices among mothers. Moreover, policymakers should consider providing breastfeeding-friendly places in workplaces and public areas to further increase exclusive breastfeeding rates and prolong the duration of breastfeeding.

\section{Declarations}

\section{Acknowledgments}

The authors are very grateful to the Kuwait Foundation for the Advancement of Sciences (KFAS) and Kuwait Institute for Scientific Research (KISR) for funding the project. The support provided by the management and other departments of KISR is gratefully acknowledged.

The authors are indebted to all mothers and infants participating in the study and recognize the excellent collaboration among all participating institutions (KISR, Ministry of Health represented by the Maternity Hospital, Public Authority for Food and Nutrition and Dasman Diabetes Institute).

\section{Competing Interest:}

The author(s) declare that they have no competing interests.

*Ethics approval and consent to participate: ethical approval was obtained from the Kuwait Ministry of Health as a participants consent form which attached on the file submitting page entitled (participates consent form and data collection sheet).

\section{*Consent for publication}

Kuwait Foundation for the Advancement of Sciences (KFAS) has no problem to publish this research.

\section{*Availability of data and material}

All Data available in Kuwait Institute for Scientific Research (KISR) and also available in paper.

\section{*Competing interests}

The author(s) declare that they have no competing interests. 


\section{*Funding}

Funding was taken from the Kuwait Foundation for the Advancement of Sciences (KFAS) and Kuwait Institute for Scientific Research (KISR)

\section{*Authors' contributions}

1. Tahani Al-Waalan is a task leader in the project and was responsible for the following activities:

- Statistical analysis using (The SAS version 9.4 (SAS Institute).

- Contributed on the survey, data collection and Data entry.

- Reporting.

\section{tahanialwaalan@gmail.com}

2. Tareq Al-Aati is the project leader and was responsible for the following activities

- Questionnaire design.

- Reporting and findings.

- Supervised the survey.

- Data management.

tareqalaati@gmail.com

3. Salwa Al-Mutairi is a task leader in the project and was responsible for data entry and contributed on the survey.

\section{skmutairi@kisr.edu.kw}

\section{*Acknowledgements}

The authors are very grateful to the Kuwait Foundation for the Advancement of Sciences (KFAS) and Kuwait Institute for Scientific Research (KISR) for funding the project. The support provided by the management and other departments of KISR is gratefully acknowledged.

The authors are indebted to all mothers and infants participating in the study and recognize the excellent collaboration among all participating institutions (KISR, Ministry of Health represented by the Maternity Hospital, Public Authority for Food and Nutrition and Dasman Diabetes Institute).

\section{References}

1. WHO; 2008. World Health Organization, Indicators for Assessing Infant and Young Child Feeding Practices, Washington D.C. Geneva, https://apps.who.int/nutrition/publications/infantfeeding/9789241596664/en/index.html 
2. Stuebe, A., 2009. The Risks of Not Breastfeeding for Mothers and Infants. [online] PubMed Central (PMC). Available at: https://www.ncbi.nlm.nih.gov/pmc/articles/PMC2812877/

3. Eufic.org. 2021. The benefits of breastfeeding for parents and baby. [online] Available at: <https://www.eufic.org/en/healthy-living/article/the-benefits-of-breastfeeding-for-parents-and-baby> [Accessed 25 October 2021].

4. Al-Kandari, H., Al-Abdulrazzaq, D., Davidsson, L., Sharma, P., Al-Tararwa, A., Mandani, F., Al-Shawaf, F., Al-Hussaini, F., Qabazard, M., Haddad, D., Al-Mahdi, M., Al-Jasser, F., Alanezi, A., Al-Sanea, H., AlBasari, I., Al-Adsani, A., Shaltout, A. and AbdulRasoul, M., 2019. Incidence of Type 2 Diabetes in Kuwaiti Children and Adolescents: Results from the Childhood-Onset Diabetes Electronic Registry (CODeR).

5. Dashti, M., Scott, J., Edwards, C. and Al-Sughayer, M., 2010. Determinants of breastfeeding initiation among mothers in Kuwait.

6. Krol, K. and Grossmann, T., 2018. Psychological effects of breastfeeding on children and mothers.

7. Dashti, M., Scott, J., Edwards, C. and Al-Sughayer, M., 2014. Predictors of Breastfeeding Duration among Women in Kuwait: Results of a Prospective Cohort Study.

8. Who.int. 2021. Ten steps to successful breastfeeding. [online] Available at: <https://www.who.int/teams/nutrition-and-food-safety/food-and-nutrition-actions-in-healthsystems/ten-steps-to-successful-breastfeeding>

9. Taha, Z., Ali Hassan, A., Wikkeling-Scott, L. and Papandreou, D., 2021. Factors Associated with Delayed Initiation and Cessation of Breastfeeding Among Working Mothers in Abu Dhabi, the United Arab Emirates.

10. Kornides, M. and Kitsantas, P., 2013. Evaluation of breastfeeding promotion, support, and knowledge of benefits on breastfeeding outcomes.

11. Baby-friendly Hospital Initiative. [online] Available at: <https://apps.who.int/nutrition/topics/bfhi/en/index.html> 2021.

12. Al-Mamari, T., Al-Ghafri, M., Al-Wahaibi, M., Ambusaidi, S. and Hassan, H., 2017. Breast Feeding and Bottle (formula) Feeding Habits among Omani Babies.

13. Nasser, A., Omer, F., Al-Lenqawi, F., Al-awwa, R., Khan, T., El-Heneidy, A., kurdi, R. and Al-Jayyousi, G., 2018. Predictors of Continued Breastfeeding at One Year among Women Attending Primary Healthcare Centers in Qatar: A Cross-Sectional Study.

14. Ncbi.nIm.nih.gov. 2011. Barriers to Breastfeeding in the United States. [online] Available at: <https://www.ncbi.nlm.nih.gov/books/NBK52688/>

15. V. Fernandes, E. dos Santos, A. L. Erdmann, D. E. de Pires, M. Zampieri and V. Gregório, 2016. Establishment of lactaton rooms in public and private companies: potentialities and difficulties, Rev. Gaúcha Enferm. 